\title{
Sistema de ciudades medias y aglomeraciones urbanas andaluzas frente al futuro.
}

\author{
Almudena Arias Sierra \\ Departamento de Urbanismo, Universidad de Sevilla, Sevilla, España \\ E-mail: ariasarqts@gmail.com
}

\begin{abstract}
Resumen. Andalucía, situada al Sur de España, como estratégica charnela de unión entre el Mediterráneo y el Atlántico, entre Europa y África, es una región de antigua urbanización, cuya tradicional estructura policéntrica e importante y representativo nivel intermedio de poblamiento (municipios entre 10.000 y 100.000 habitantes), son entendidos como capital territorial de gran valor. Esta estructura policéntrica ha pervivido bajo una concepción provincialista con fuerte arraigo de casi dos siglos. El Plan de Ordenación Territorial de Andalucía (POTA), apostó abiertamente por un modelo de ciudad compacta, versión fisica de la ciudad mediterránea, permeable, diversificada, y consolidó también un modelo territorial de un nivel jerárquico superior constituido por diez Centros Regionales (8 capitales provinciales, Jerez y Algeciras). De este modo, además de una discutida visión igualitaria de la jerarquía urbana superior, correspondiente a aglomeraciones urbanas muy disimiles entre sí, plantea la potencialidad de un sistema de ciudades medias urbanas como la verdadera oportunidad andaluza que permita emerger a la región en el contexto europeo e internacional. Así, fenómenos urbanos de gran interés en el interior (redes de ciudades medias de la Vega, Sur de Córdoba) y en el litoral (agroindustria poniente, Costa del Sol-Occidental, Aglomeración Urbana de Málaga) están mostrando una nueva vitalidad de las ciudades medias que merecen una especial atención.

Trataremos de hacer balance de respuestas dada hasta ahora respecto a la estrategia territorial andaluza del POTA, al impulso de nuevos objetivos como el respeto al funcionamiento de los territorios, las ciudades y los pueblos como sistema, destacando también, en el contexto del debate entre difusión y compacidad, el papel desempeñado por la gran extensión de territorio andaluz ambientalmente protegido y/o implicado en la producción agropecuaria.
\end{abstract}

Palabras clave: planeamiento territorial, ciudad media, sostenibilidad.

\section{Introducción}

A partir de los años 90 en España, y tras un modo de hacer planeamiento centrado en la ciudad y el hecho urbano, se empieza a apreciar la necesidad de una "Nueva Cultura del Territorio" (VEGARA, 1993) que pueda superar la óptica municipalista de los problemas. Este nuevo enfoque de los problemas urbanos reclamaba entre otros aspectos:

Una Estrategia de ordenación Territorial al Servicio de los Objetivos de Desarrollo y Bienestar, el protagonismo del Sistema de Ciudades y una atención especial a la Escala Territorial Intermedia basada en las Áreas Funcionales del Territorio.

En el panorama español, esta última característica de especial vigilancia a la Escala Territorial Intermedia suponía una nueva política de ordenación del territorio coherente no sólo con una identidad regional, sino más aún, en un marco más próximo al ciudadano, 
respetuosa con una identidad comarcal. Si bien, ciertamente que en España, esta realidad territorial intermedia de la escala comarcal es muy diversa según las diferentes Comunidades Autónomas. No obstante, en aquel momento las intervenciones a escala territorial intemedia se postulaban como esenciales «para conseguir la incorporación de las áreas rurales a los procesos de desarrollo y paliar el deterioro de sus estructuras económicas, socilaes y demográfocas a traves de la creación de equipamientos, dotaciones y alicientes de diverso tipo en las cabeceras comarcales con criterios de solidaridad, racionalidad y eficacia.»(VEGARA, 1993). Para ello era también necesario una delimitación previa, un "Área Funcional" que podían obedecer a criterios de índole administrativa, geográfica, judicial o funcional,constituidas por la ciudad de cabecera y aquellas otras que quedaban bajo su ámbito de influencia.

Curiosamente, ya en la Comunidad Autónoma de Andalucía se había elaborado en el año 83 una Propuesta de Comarcalización de Andalucía que suponía una primera aproximación a la organización funcional de la región. Esta comarcalización, que se vincularía en el año 86 al Sistema de Ciudades, se revelaba como instrumento esencial para la comprensión de las relaciones regionales. No
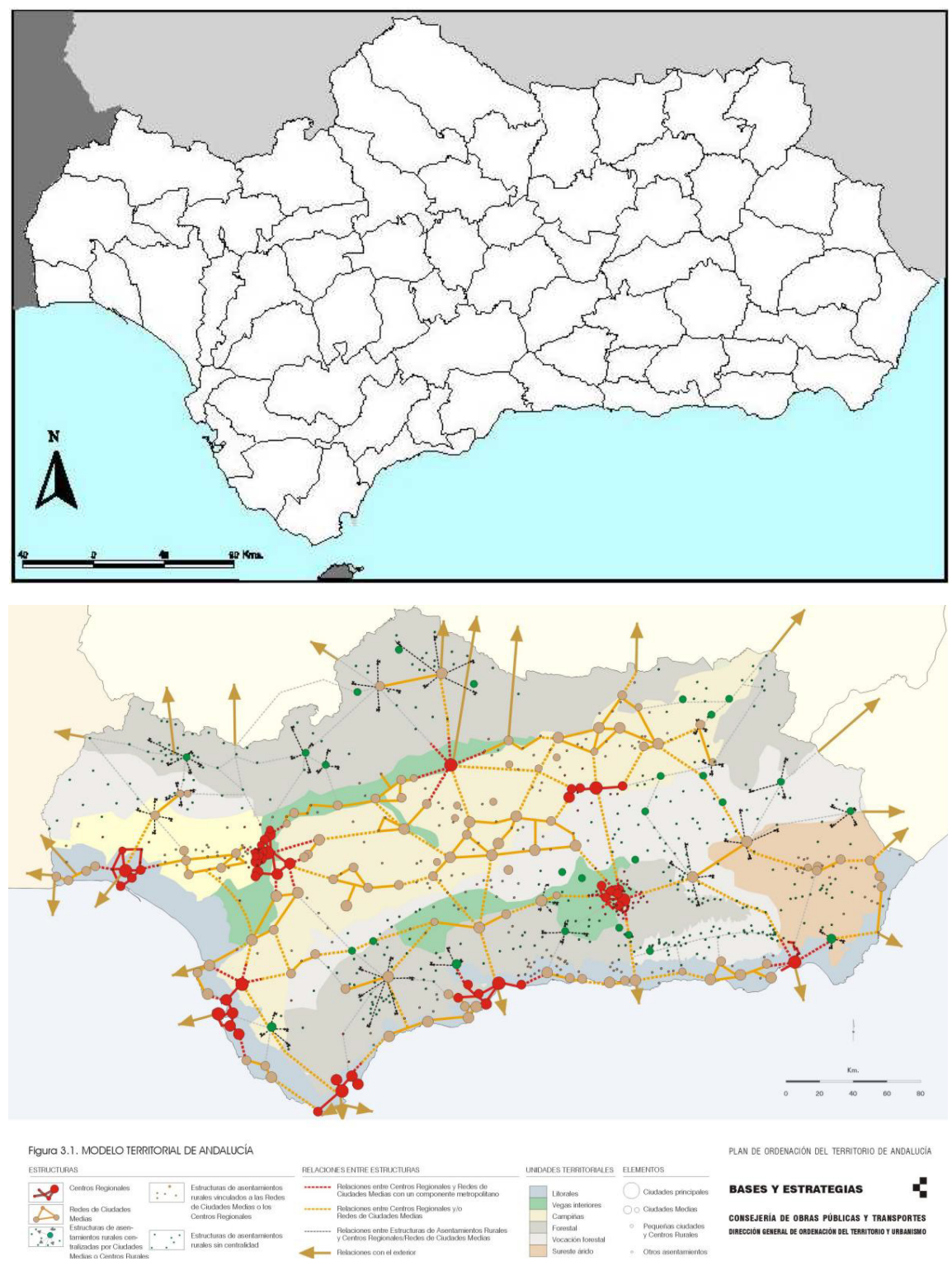

Fig. 1. (arriba). Fig.2. (abajo) 
obstante, las políticas posteriores abandonan estos planteamientos habiendo quedado hoy la comarcalización fuera del debate político, y habiendo perdido por el momento la posibilidad de convertirla en instrumento de referencia en el desarrollo del modelo territorial de Andalucía (RODRÍGUEZ, 2010). En su lugar, se ha visto cobrar impulso al centralismo provincialista, con fuerte arraigo de casi dos siglos, o localista, representado en las diputaciones provinciales. (Véase Fig.1. y Fig.2.).

Y efectivamente, al Plan de Ordenación del Territorio de Andalucía (POTA), que constituye en la actualidad el instrumento mediante el cual se establecen los elementos básicos de la organización y estructura del territorio de la Comunidad Autónoma, siendo el marco de referencia territorial para los demás planes y la acción pública en general, consolida la visión de un nivel jerárquico superior constituido por diez Centros Regionales, es decir, todas la capitales provinciales más Jerez y Algeciras. La definición de diez Centros Regionales establecida por el POTA induce a una cierta confusión conceptual, pues «por centros regionales debe entenderse, como su propio nombre indica, a aquellos que tienen un área de influencia de ámbito regional» (Feria, 2007) además de potenciar el centralismo provincial del que hablabamos. Dejando a un lado el debate de que esta visión de organización jerárquica del sistema urbano andaluz se aparta de la propia realidad de la jerarquía urbana andaluza, o que pueda cumplir los papeles tanto de organización interna como de articulación a escala europea y global, que hoy día se llevan a cabo esencialmente a través de las grandes ciudades, el Modelo territorial del POTA definía entonces el Sistema de Ciudades del siguiente modo:

El Sistema de Ciudades: como Estructuras de asentamientos urbanos y rurales de relación con capacidad de conformar redes o sistemas territoriales tales como:

-El Sistema Polinuclear de Centros Regionales

-Las Redes de Ciudades Medias,

-Las Redes Urbanas en Áreas Rurales.

Basados en una jerarquía urbana de tres categorías básicas de las ciudades y asentamientos de la región:

-Ciudades principales: cabeceras del sistema y componentes básicos de los Centros Regionales;

-Ciudades Medias, con dos niveles internos en consideración de su diferente tamaño demográfico, diversidad y dinámica de su base económica y peso funcional;

-Centros Rurales o Pequeñas Ciudades; igualmente subdivididas en dos niveles jerárquicos

Y finalmente ,el resto de asentamientos.

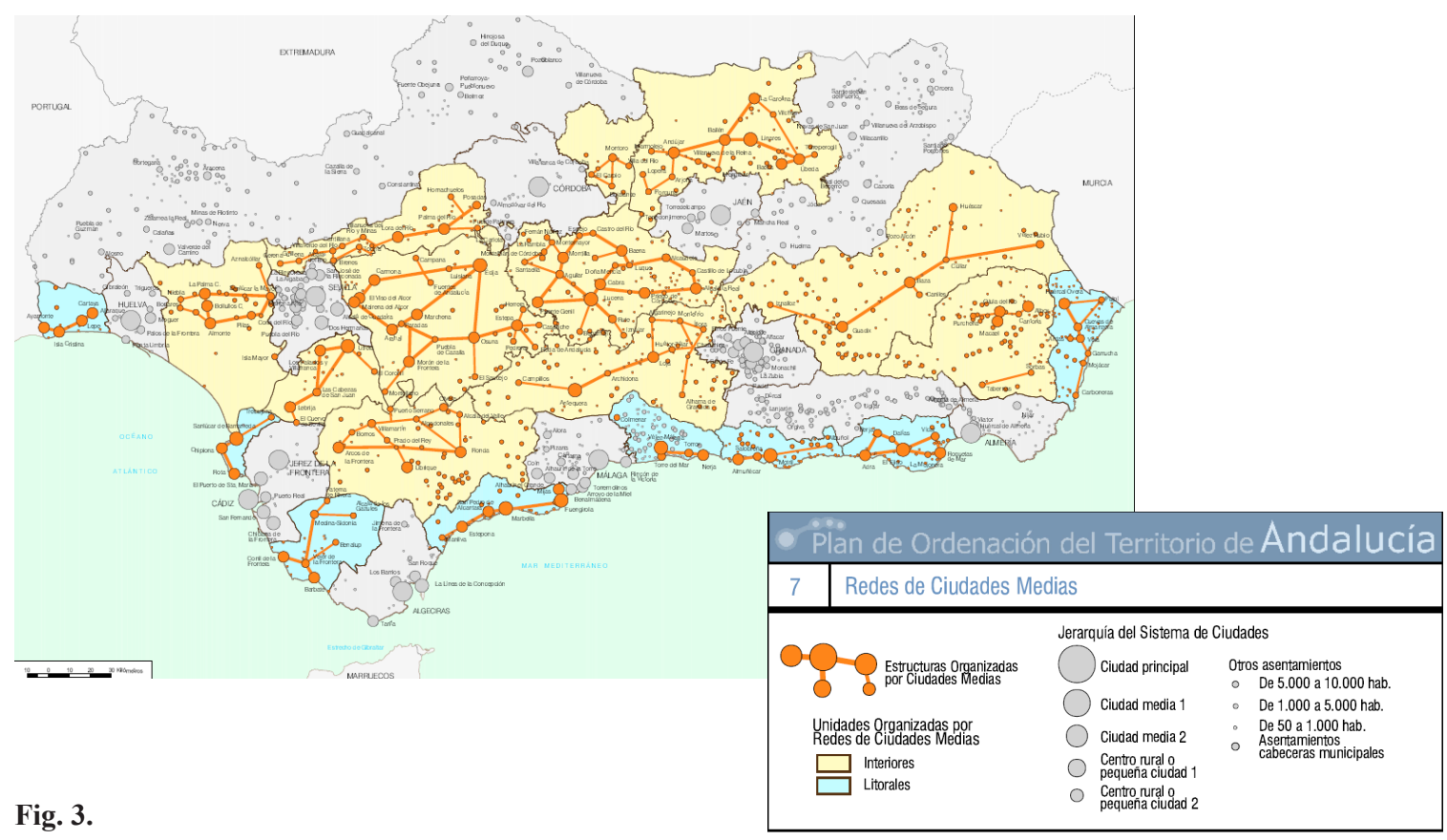




\section{La atención a la escala Intermedia.}

El propio POTA nos definirá el Sistema Urbano Andaluz como un Sistema de Ciudades formado por «el conjunto de asentamientos de la región, desde las grandes ciudades hasta los pequeños núcleos rurales, y sus relaciones de articulación a todas las escalas» (POTA, 2006), donde resulta de especial interés la incorporación del concepto de «red» al entendimiento del sistema urbano (RODRÍGUEZ, 2010).

De este modo, podríamos sintetizar que actualmente el Sistema Urbano Andaluz, se caracteriza por un conjunto urbano estructurado, de forma policéntrica, en un nivel jerárquico superior $\mathrm{y}$ un importante y representativo nivel intermedio de poblamiento, entendido éste como el constituido por los municipios entre 10.000 y 100.000 habitantes según los documentos de planificación andaluces. Dicha sección intermedia, que no ciudad media sino red de ciudades, sirve de enlace entre las cada vez más pobladas aglomeraciones urbanas (interiores y litorales) y el mundo rural andaluz, y en cierto modo vendría a asumir el papel que años antes se planteaban para las áreas comarcales. En este hecho reside la principal característica del sistema de ciudades de Andalucía y las políticas públicas han ido encaminadas a defender y potenciar esta propiedad del sistema territorial regional. (Véase Fig.3.)

En efecto, esta organización urbana, constituye un referente básico del Modelo Territorial perseguido por el POTA para el diseño de sus Estrategias de Desarrollo, que sin embargo, no puede ser entendida como un artificio desligado de continuo territorial en el que se localiza. El funcionamiento y la sostenibilidad global del Sistema de Ciudades están condicionados por un envolvente de recursos naturales con el que dicho Sistema mantiene vínculos económicos y ecológicos. En ese sentido, el Modelo Territorial de Andalucía es, básicamente, la expresión de un orden que resulta de fomentar y consolidar las relaciones cooperativas entre ciudades y asentamientos, y entre éstos y el territorio y los recursos naturales.

Tal vez por ello una de las Estrategias de Desarrollo Territorial que plantea el POTA, líneas de actuación para la onsecución del Modelo Territorial, núcleo central y más desarrollado de las propuestas del Plan, la constituye el Sistema Regional de Protección del Territorio. Así el Plan establece como

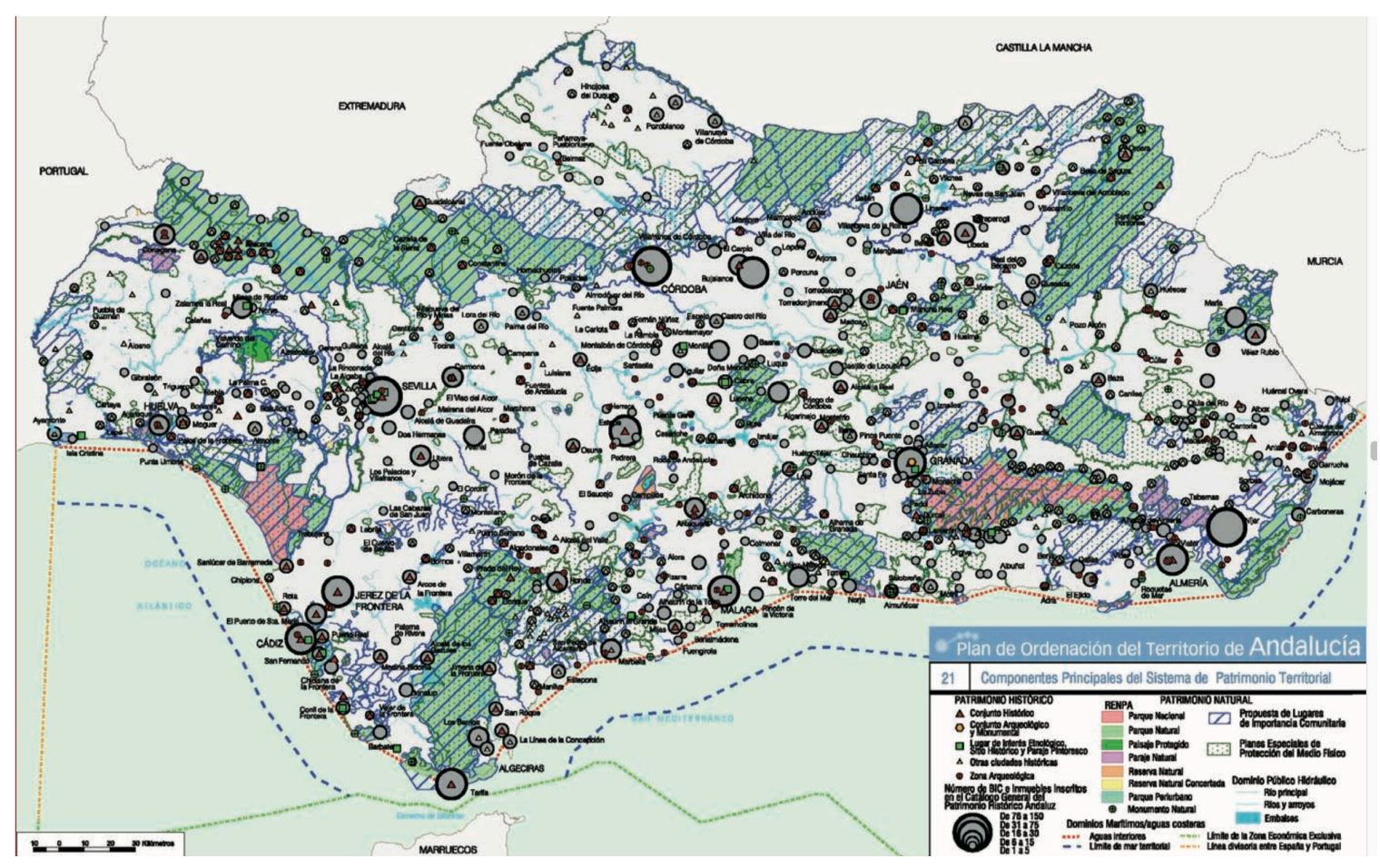

Fig. 4 
una componente fundamental de la estructura territorial de Andalucía, y de su articulación regional, los distintos bienes y espacios pertenecientes al patrimonio, tanto natural como cultural y el paisajístico. (Véase Fig.4.)

Por otro lado, además del Plan de Ordenación del Territorio de Andalucía, la Ley 1/1994, de 11 enero, de Ordenación del Territorio de la Comunidad Autónoma de Andalucía, establecía otros importantes instrumentos de planificación territorial integral como eran Los Planes Ordenación del Territorio de Ámbito Subregional. Pero especialmente para la formulación de los Planes de Ordenación del Territorio de ámbito subregional, el POTA constituye el marco de referencia más amplio que debía ser tenido en cuenta, estableciendo los ámbitos en los que resulta conveniente y
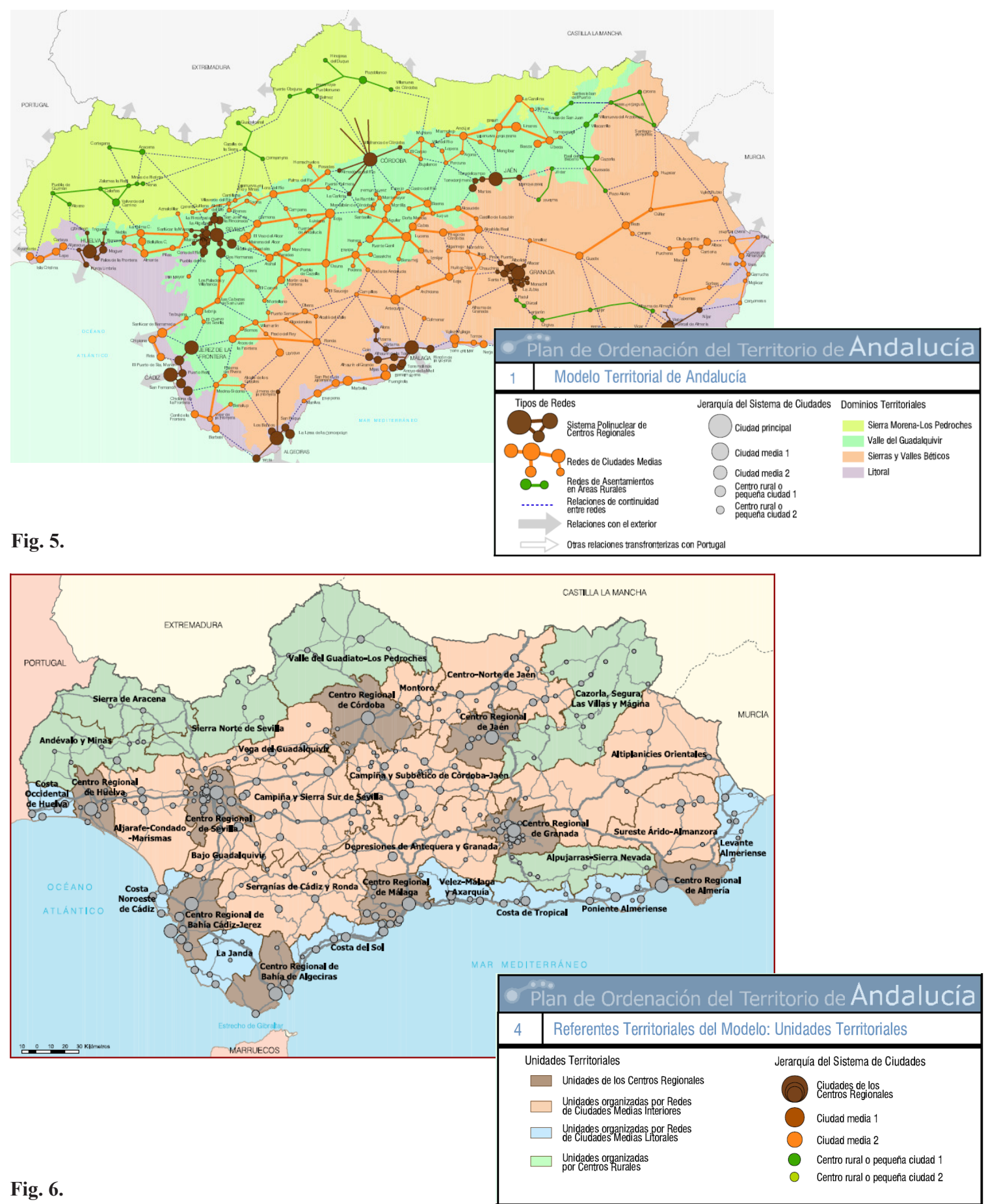
necesaria su formulación y aprobación.. En este sentido el POTA establecía una Zonificación del territorio regional en Dominios y Unidades Territoriales, ámbitos inferiores al conjunto regional, o de escala intermedia, donde los Dominios Territoriales se superponen no muy ajustadamente sobre las Unidades Territoriales dificultando la inscripción del sistema de protección y de uso sostenible de los recursos naturales diseñado la región (RODRÍGUEZ, 2010).

-Dominios Territoriales. a) Sierra MorenaLos Pedroches. b) Valle del Guadalquivir. c) Sierras y Valles Béticos. d) Litoral.

-Unidades Territoriales. Cuya zonificación en Unidades Territoriales responde a una consideración cruzada del conjunto de los referentes del Modelo antes enunciados: Sistema de Ciudades, Esquema Básico de Articulación Territorial y Dominios Territoriales. Las Unidades Territoriales son áreas continuas definidas por su homogeneidad física y funcional, así como por presentar problemas y oportunidades comunes en materias relacionadas con el uso económico del territorio y la gestión de sus recursos patrimoniales. Estas Unidades guardan, a grandes rasgos, correspondencia geográfica con la organización del Sistema de Ciudades, y son referentes básicos para el desarrollo de estrategias territoriales. Se diferencian las siguientes Unidades Territoriales:

- Centros Regionales;

-Unidades Territoriales Litorales basadas en Redes de Ciudades Medias.

- Unidades Territoriales Interiores basadas en Redes de Ciudades Medias y Unidades Territoriales organizadas por Centros Rurales.

- Unidades organizadas por Ciudades Medias o Centros Rurales que constituyen redes de asentamientos netamente rurales. Geográficamente estas Unidades ocupan tres tipos de áreas o dominios físicos: Sierra Morena, el Subbético oriental y el Penibético oriental. (Véase Fig. 5 y Fig. 6)

«A estos ámbitos están referidas ciertas determinaciones complementarias motivadas por las particularidades físiconaturales y de los aprovechamientos socio-económicos de los recursos de cada uno de ellos. Asimismo, son referencias necesarias para la organización funcional del territorio y para el desarrollo de procesos de planificación integral y sectorial de ámbito subregional y, en su caso, local.» (POTA, 2006).

Por tanto para el POTA "escala subregional" y "escala intermedia" son sinónimos de lo que hubiéramos podido llamar en su día "escala comarcal", con la diferencia que este último incluye una componente de identidad y de identificación de la población con su territorio que no llega a percibirse en los dos primeros. En efecto, desde un enfoque más administrativista, la propia Ley 1/1994 determina que el ámbito de los planes subregionales abarcará necesariamente «el conjunto de términos municipales completos $\mathrm{y}$ contiguos, que por sus características físicas, funcionales y socioeconómicas conformen un área coherente de planificación territorial y, en su caso, respetará las áreas definidas en el Plan de Ordenación del Territorio de Andalucía.»

La importancia de estos planes subregionales es tal resultan ser vinculantes para los Planes con Incidencia en la Ordenación el Territorio y el Planeamiento Urbanístico General, independientemente de que las determinaciones que adopten tengan el carácter de Norma (determinaciones de aplicación directa en los suelos urbanizables y no urbanizables), Directrices (determinaciones vinculantes en cuanto a sus fines) o Recomendaciones (determinaciones de carácter indicativo).

El POTA establecía entre las determinaciones a adoptar para la Ordenación Territorial en los Centros Regionales el dotarlos con Planes de Ordenación del Territorio de ámbito subregional [SC-01]. La elaboración de estos planes debe entenderse como un instrumento de profundización en los enfoques metropolitanos, incluyendo la coordinación de los planes urbanísticos de los respectivos municipios. Igualmente dejaba previstos estos planes en los territorios organizados por las Redes de Ciudades Medias, donde el grado de madurez y complejidad alcanzado planteaba la necesidad de abordar estos instrumentos de ordenación territorial, tanto próximas a áreas metropolitanas como en aquellas áreas rurales que así lo precisen teniendo en cuenta su complejidad, y, entre otros factores, la importancia del patrimonio urbano y 
natural que es necesario preservar. El ámbito de referencia para estos planes serían las Unidades Territoriales, sin perjuicio de que en su formulación se ajustara su delimitación, tras los estudios y justificación pertinente.

No obstante la prioridad en la redacción de estos planes subregionales se han centrado en las principales áreas urbanas de Andalucía, estos es, Centros Regionales o actuales aglomeraciones urbanas y unidades territoriales del Litoral, que se corresponden con las áreas más dinámicas y tensionadas de la región.

Aún así, estos planes adoptan determinaciones en relación a tres grandes bloques de contenidos:

La estructura del territorio y los sistemas de articulación (sistema de asentamientos, sistema de comunicaciones y transportes, infraestructuras básicas y la red de espacios libres de interés supramunicipal).

La ordenación de usos en el territorio (usos productivos de interés supramunicipal, áreas de oportunidad, ordenación del uso agrícola, etc).

La protección del territorio (espacios protegidos por legislación sectorial o por el propio plan territorial y la prevención de riesgos).

Actualmente, el conjunto de planes subregionales abarca 21 ámbitos territoriales en distintas fases según podemos apreciar en el cuadro siguiente:

Tabla 1. Magnitudes de los ámbitos de los planes de ordenación del territorio de ámbito subregional en Andalucía.

\begin{tabular}{|c|c|c|c|c|}
\hline Ámbitos & $\begin{array}{l}\text { Población } \\
2010\end{array}$ & $\begin{array}{l}\mathrm{N}^{\circ} \\
\text { municipios }\end{array}$ & $\begin{array}{l}\text { Superficie } \\
(\mathrm{km} 2)\end{array}$ & $\begin{array}{l}\text { Estado de } \\
\text { tramitación }\end{array}$ \\
\hline $\begin{array}{l}\text { Aglomeración urbana } \\
\text { de Granada }\end{array}$ & 529.678 & 34 & 972,62 & Aprob. 1999 \\
\hline $\begin{array}{l}\text { Aglomeración urbana } \\
\text { de Sevilla }\end{array}$ & \begin{tabular}{|l|}
1.535 .38 \\
$(2016)$ \\
\end{tabular} & 46 & 4.905 .04 & Aprob. 2009 \\
\hline $\begin{array}{l}\text { Aglomeración Urbana } \\
\text { de Jaén }\end{array}$ & $\begin{array}{l}222.844 \\
(2015)\end{array}$ & 15 & $1.761,00$ & Aprob. 2014 \\
\hline $\begin{array}{l}\text { Aglomeración urbana } \\
\text { de Córdoba }\end{array}$ & 361.054 & 8 & 2.333 .67 & $\begin{array}{l}\text { Acuerdo } \\
\text { Formulación. } 2011\end{array}$ \\
\hline \multicolumn{5}{|c|}{ CENTROS REGIONALES LITORALES } \\
\hline $\begin{array}{l}\text { Revisión: Bahía de } \\
\text { Cádiz-Jerez }\left(^{*}\right)\end{array}$ & 205.364 & 6 & $1.186,5$ & $\begin{array}{l}\text { Acuerdo } \\
\text { Formulación. } 2011\end{array}$ \\
\hline $\begin{array}{l}\text { Aglomeración urbana } \\
\text { de Málaga }\end{array}$ & $\begin{array}{l}888.986 \\
(2013) \\
\end{array}$ & 13 & $1.330,0$ & Aprob. 2009 \\
\hline $\begin{array}{l}\text { Aglomeración urbana } \\
\text { de Almería }\end{array}$ & \begin{tabular}{|l|}
258.722 \\
$(2016)$ \\
\end{tabular} & 9 & $1.159,0$ & Aprob. 2011 \\
\hline $\begin{array}{l}\text { Campo de Gibraltar } \\
\text { (Cádiz) }\end{array}$ & \begin{tabular}{|l|}
264.290 \\
$(2014)$ \\
\end{tabular} & 7 & $1.514,4$ & Aprob. 2011 \\
\hline $\begin{array}{l}\text { Aglomeración urbana } \\
\text { de Huelva }\end{array}$ & 239.985 & 8 & 968 & $\begin{array}{l}\text { Acuerdo } \\
\text { Formulación. } 2008\end{array}$ \\
\hline \multicolumn{5}{|c|}{ UNIDADES ORGANIZADAS POR REDES DE CIUDADES MEDIAS LITORALES } \\
\hline Poniente de Almería & 248.079 & 9 & 969,7 & Aprob. 2002 \\
\hline $\begin{array}{l}\text { Costa del Sol } \\
\text { occidental (Málaga) }\end{array}$ & 379.334 & 9 & 941,2 & $\begin{array}{l}\text { Aprob. } 2006 \\
\text { ANULADO }\end{array}$ \\
\hline
\end{tabular}




\begin{tabular}{|l|l|l|l|l|}
\hline $\begin{array}{l}\text { Litoral occidental de } \\
\text { Huelva }\end{array}$ & 105.703 & 7 & 732,1 & Aprob. 2006 \\
\hline $\begin{array}{l}\text { Litoral oriental - } \\
\text { Axarquía (Málaga) }\end{array}$ & 165.224 & 29 & 985,9 & Aprob. 2006 \\
\hline Levante de Almería & 90.325 & 11 & $1.198,6$ & Aprob. 2009 \\
\hline $\begin{array}{l}\text { Costa noroeste de } \\
\text { Cádiz }\end{array}$ & 121.201 & 4 & 360,7 & Aprob. 2011 \\
\hline La Janda (Cádiz) & 87.380 & 7 & $1.535,4$ & Aprob. 2011 \\
\hline $\begin{array}{l}\text { Costa Tropical de } \\
\text { Granada }\end{array}$ & 127.613 & 17 & 786,7 & \\
\hline UNIDADES ORGANIZADAS POR REDES DE CIUDADES MEDIAS INTERIORES \\
\hline Ámbito de Doñana & 125.401 & 13 & $2.736,4$ & Aprob. 2004 \\
\hline Sur de Córdoba & 275.443 & 31 & $3.444,0$ & Aprob. 2012 \\
\hline $\begin{array}{l}\text { Alto Almanzora } \\
\text { (Almería) }\end{array}$ & 58.800 & 28 & $1.768,2$ & En estudio \\
\hline UNIDADES ORGANIZADAS POR CENTROS RURALES & \\
\hline $\begin{array}{l}\text { Sierra de Segura } \\
\text { (Jaén) }\end{array}$ & 26.649 & 13 & $1.932,7$ & Aprob. 2003 \\
\hline $\begin{array}{l}\text { Sierra de Aracena } \\
\text { (Huelva) }\end{array}$ & 39.854 & 29 & $3.015,0$ & En estudio \\
\hline Centro Norte de Jaén & 277.29735 & 35 & $4.856,3$ & En estudio \\
\hline Total POTs & 6.833 .377 & 384 & $41.535,5$ & \\
\hline Total Andalucía & 8.202 .220 & 770 & $87.597,0$ & \\
\hline \% Andalucía & 83,3 & 49,9 & 47,4 & \\
\hline
\end{tabular}

(*)Datos referidos al municipio de Jerez de la Frontera. Fuente: Consejería de Vivienda y Ordenación del Territorio.

Esto permite, que el grado de cobertura de estos planes se extienda a medio-largo plazo a más $80 \%$ de la población, y casi al $50 \%$ de los municipios en un $47.4 \%$ de superficie. (Véase Fig. 7)

Uno de los más recientes planes subregionales, y más significativo por el conjunto tan pujante de ciudades medias, lo constituye el ámbito del SUR DE CÓRDOBA, en zona central de ANDALUCÍA. Su ubicación entre las provincias de Sevilla, Jaén, Granada y Málaga presenta como una de sus principales características su elevada accesibilidad territorial y su conectividad con la mayoría de los centros regionales del sistema andaluz de ciudades.

\section{Conclusiones}

La actitud técnico política que se desarrolla en el POTA viene a significar una toma de posición respecto a los procesos de desestructuración urbana del territorio, que constituyen una realidad evidente en nuestra actualidad. Esta reacción se desentiende de los planteamientos fatalistas, que asumen como única forma líder de desarrollo urbano aquella que viene siendo y en la que las aglomeraciones urbano territoriales constituyen de por sí la única fórmula válida que aporta significado, como forma actualmente existente y heredada para la estructuración de los futuros desarrollos urbanos.

El intento del POTA por recuperar una forma 


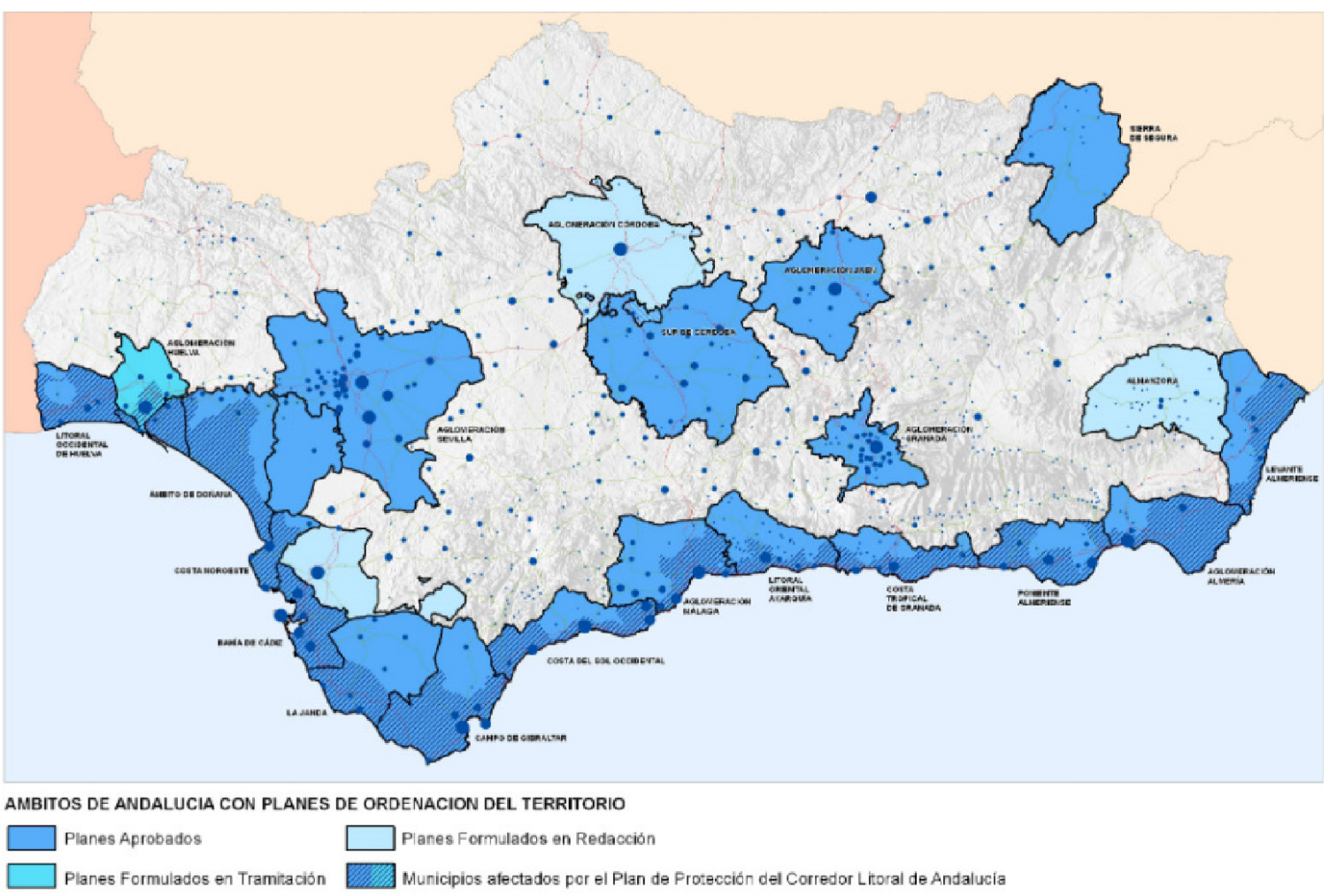

Fig. 7.

de desarrollo del territorio que fundamente una estructura futura que supere esta fuerte concentración de población-actividades, en la que el efecto sumidero de los grandes centros regionales se impone, es sin duda un esfuerzo válido en lo que tiene como fórmula de potenciar un sistema de ciudades que rompa el monolitismo de las grandes concentraciones que actualmente se están desarrollando. En este sentido, el POTA forma parte de una tradición, intentándo profundizar y continuar planteamientos que están en la base histórica de la ordenación territorial.

Una de las claves de su propuesta para un equilibrio urbano-territorial reside, en gran medida, en el afianzamiento y recuperación de un sistema de ciudades medias, cuyo reconocimiento $\mathrm{y}$ fortalecimiento suponen una forma de equilibrar la población y las actividades en el territorio, produciendo así un nuevo urbanismo, que debería ser capaz de cubrir de forma equilibrada todas las necesidades de las nuevas poblaciones. En un sentido amplio, el alcance de este planteamiento excede el de la planificación territorial convencional, como asimismo es mas amplio que los de la planificación de ámbito social o de carácter ecológico-ambiental, comprendiendo un modelo territorial transversal, que formula una forma distinta de comportarse frente al territorio.

No obstante, el propio desarrollo del documento en sus normativas y planificaciones subsidiarias ha sido un proceso con más sombras que luces, que ha distorsionado en gran medida el marco inicialmente establecido. Un ejemplo de ello es la permisividad ante la progresiva alteración del sistema de asentamientos. En este sentido, el sistema de asentamientos andaluz existente era concebido como el ejemplo de un soporte poblacional largamente urdido por el tiempo y con amplias posibilidades de proyección, pero eso no ha evitado la paradoja de que determinados planes subregionales estableciesen unas muy injustificadas necesidades de intervenciones estratégicas, que rompían con nuevas implantaciones esa estructura existente, ocultando la trasgresión mediante el expediente de no designarlos como nuevos asentamientos, aunque de hecho lo fueran. En las redes de ciudades medias, el litoral ha sido un ejemplo de estas actitudes por la presión de la industria turística.

Con carácter general, podría decirse que, 
en cierto modo, el POTA se enfrenta con el ya viejo problema de las teorías clásicas en relación con los niveles mínimos o máximos de población, y aún sin decirlo explícitamente se enfrenta a los niveles organización del territorio en cuanto a los conceptos de superpoblación, infrapoblación y óptimo. Esta investigación analítica del óptimo pudiera ser uno de los temas fundamentales a los que el actual plan territorial intenta dar respuesta. Esta forma de entender el POTA como investigación análitica queda no obstante restringida a consideraciones que no van más allá de lo que pueda ser una organización del territorio desde el punto de vista puramente antrogeoeconómicos que en donde aspectos como los movimientos migratorios internos y el hecho de una potente movilidad social recurrente constituyen aspectos que aunque siempre han tenido factores fundamentales en el planeamiento en cuanto a consecuencias económicas en cuanto a la forma de adaptarse la población en el territorio en el actual planeamiento territorial al que nos enfrentamos desbordan en su reestructuración como ciudades medias en lo que pudiéramos llamar nueva forma de asentamiento que conceptualmente puede servir de fundamento para entender.

Dentro de lo anteriormente expuestos en donde se plantea las consideraciones que el POTA realiza en cuanto se refiere a la organización urbana del territorio en el nuevo planeamiento que en la actualidad se está realizando en un intento por superar los graves problemas que las grandes concentraciones urbanas están planteando en el nuevo sentido que pretende establecer en el territorio dentro del intento de constituir un marco periférico a través de mecanismos en algunos momentos artificiales y que se asientan como leyes en la medida de que lo permiten los medios disponibles.

La realidad es que el POTA ha constituido una mutación o una transformación en la forma de planeamiento en donde lo que en el plan se define como unidades territoriales viene a sustituir a otros conceptos anteriores que si bien todavía se emplean en determinados conceptos e incluso ideologías en relación con el planeamiento pueden ser vigentes dentro de las nuevas maneras de entender el planeamiento.
Se situaría en un plano que quedaría en gran manera fuera de lo que en el momento actual se consideraría vigente.

Creemos que si bien el POTA viene a significar un intento de entender el planeamiento urbano territorial desde el desarrollo de una teoría en donde actitudes aleatorias que se fundamentan en planteamientos no siempre cerrados no tanto en su contenido como en su delimitación, esta actitud de un planteamiento abierto en el alcance de sus objetivos es sin duda una actitud de apertura no solo en cuanto a las necesidades que pretende cubrir sino que incluso constituye un realidad que desde su misma base es incluso desconocida por los redactores del planeamiento, lo que es el asentar ene le planeamiento una arbitrariedad que habría que entenderla como una forma de entender el plan como el asentamiento de mecanismos de toma de decisión que incluso pudiera considerarse como una negación de los propios principios de lo que ha significado históricamente el concepto del planeamiento.

En todo caso, quizá el planteamiento anteriormente expuesto se sumaría al propio sentido que en el plan se establece en relación con el alcance territorial y la delimitación que el propio POTA deja abierta en general e incluso en las áreas territoriales a que se aplica en algún sentido aun pretendiéndolo no alcanzan la dimensión de las antiguas unidades comarcales que en su antiguo contexto y alcance.

\section{Referencias}

\section{Planeamiento}

Plan de Ordenación Territorial de Andalucía. 2006. Consejería de Obras Públicas y Transportes, Junta de Andalucía.

Estrategia Andaluza de Desarrollo Sostenible 2030. 2018. Consejería de Medioambiente y Ordenación del Territorio, Junta de Andalucía.

Artículo en revista científica

José María Feria Toribio. 2007. "Análisis prospectivo Andalucía 2020. Comportamiento del sistema urbano". Centro de Estudios Andaluces. 
https://www.centrodeestudiosandaluces. es/datos/paginas/factoria/programas/ a2020/2020 sistemaurbano.pdf

Rodríguez, Francisco y Sánchez, Luis Miguel. 2010. "La planificación territorial y el sistema urbano de Andalucía. Notas para una reflexión desde la geografía". Cuadernos Geográficos, 47 (2010-2), 223245. http://www.ugr.es/ cuadgeo/docs/ articulos/047/047-009.pdf

Vegara Gómez, Alfonso. 1993. "Cultura urbana y cultura del territorio. Los retos del urbanismo del siglo XXI". Ciudad y Territorio, Vol. I, Tercera época, 95-96 (primavera-verano 1993), 245-255. 